\title{
Innovative community engagement for the quantitative risk assessment for a mine closure and reclamation plan
}

\author{
L Christoffersen SRK Consulting (Canada) Inc., Canada \\ S Reinecke Stratos Inc., Canada \\ M Shoesmith Stratos Inc., Canada \\ E McKennirey Crown-Indigenous Relations and Northern Affairs Canada, Canada \\ L Pilgrim Wood PLC, Canada \\ D Rae Wood PLC, Canada
}

\begin{abstract}
Following the discovery of gold in Yellowknife, Northwest Territories (Canada), Giant Mine officially opened in 1948. Mining activities ceased shortly after the mine's owner went bankrupt in 1999. Since 2004, the mine has been the responsibility of Crown-Indigenous Relations and Northern Affairs Canada (CIRNAC). Historical activities at the mine have resulted in the generation of arsenic trioxide dust stored in underground chambers, contaminated soil and waste rock, four tailings containment areas, seven open pits, and contaminated water and sediment in Baker Creek, which traverses the mine site. The site has been undergoing progressive reclamation to stabilise the site since 2005, with final closure activities anticipated to be implemented in 2021.
\end{abstract}

The roughly 50-year operating period of the mine resulted in significant disturbance and impacts on the health and lifestyles of local people, especially members of the Yellowknives Dene First Nation (YKDFN) and the North Slave Métis Alliance (NSMA). Giant Mine is within the Akaitcho Dene asserted territory and is close to the YKDFN communities of N'Dilo and Dettah, and is within the traditional land use area of the Tlicho, known as Mowhi Gogha De Niitlee. Giant Mine is also situated within the municipal boundaries of the City of Yellowknife.

The closure and reclamation plan for Giant Mine was submitted in April 2019 to the Mackenzie Valley Land and Water Board for approval. The Giant Mine Remediation Project (GMRP) team made decisions about closure options for Giant Mine using input from an extensive engagement process with YKDFN, NSMA, the City of Yellowknife, and other community and government stakeholders. The goals of the GMRP are to minimise public and worker health and safety risks, minimise the release of contaminants from the site into the environment, remediate the site in a way that inspires public trust, and implement an approach that is cost-effective and robust over the long-term.

As part of the approval process to commence remediation activities, the project team is required to complete a quantitative risk assessment (QRA). There is an explicit requirement to determine acceptability thresholds in consultation with potentially affected communities and to examine risks from a holistic perspective that includes environmental, social, health, and financial effects. The approval and implementation of the closure and reclamation plan is also occurring within the broader context of reconciliation with Indigenous people in Canada and growing requirements for the federal government to meaningfully engage Indigenous people on actions affecting their lands and resources. Together, these requirements present a unique challenge for the Giant Mine QRA as potentially affected communities rarely participate in, or provide specific input to, a QRA process. An extensive literature review found no publicly available documentation of community involvement in QRAs conducted in natural resource industries.

Consequently, the GMRP team and its consultants had to develop an innovative, fit-for-purpose engagement strategy to complete the QRA. This strategy is described herein, and specific outcomes of engagement with Indigenous and stakeholder groups are provided. 
Keywords: Indigenous communities, stakeholder engagement, community engagement, quantitative risk assessment, closure plan

\section{Introduction}

Giant Mine (the site) is an inactive gold mine located approximately $5 \mathrm{~km}$ north of the centre of Yellowknife, Northwest Territories, Canada (Figure 1). Gold was mined underground via three shafts and above-ground in eight pits. Ore was milled onsite in a 1,000 imperial tons per day mill with circuits for ore crushing, grinding, froth flotation, and mercury amalgamation, and in 1949, roasting of the ore began. The mine produced gold from 1948 until 1999, after which stewardship was transferred to the Department of Indian and Northern Affairs Canada, now Crown-Indigenous Relations and Northern Affairs Canada (CIRNAC). All mining activities ceased in July 2004, after which CIRNAC reassumed stewardship and a contractor was retained to operate and maintain the site in compliance with current regulations.

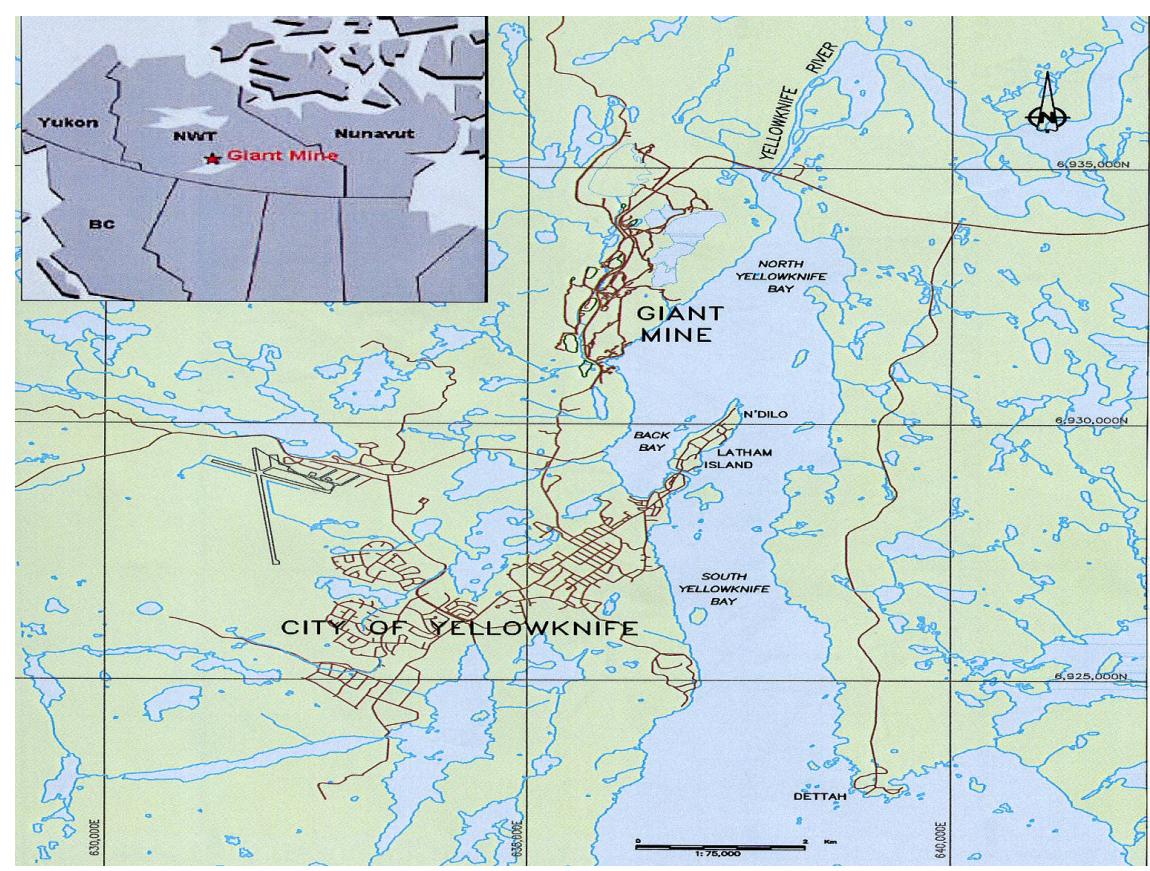

Figure 1 Location of Giant Mine, near Yellowknife, Northwest Territories, Canada

The roughly 50 years of mining resulted in significant disturbance to the land and water, and impacted the health and lifestyles of local people, especially members of the Yellowknife Dene First Nation (YKDFN) and the North Slave Métis Alliance (NSMA). In general, Indigenous communities and other local groups were not consulted on the site throughout most of its operating life.

Early in 2015, the project team initiated an engagement process related to plans for the remediation of surface of the site. More than 100 people from Yellowknife, Dettah, and N'Dilo (Figure 1) participated in the surface design engagement process, which allowed local people to have input to the closure and reclamation plan for the surface of the site and ensured that the project team understood the perspectives and preferences of different stakeholder groups.

The project team has made many decisions about how to clean up the site based on the outcomes of the surface design engagement process. These decisions are captured in the closure and reclamation plan that was submitted to the Mackenzie Valley Land and Water Board (Board) on 1 April 2019. Once the Board approves the plan, the site will receive its water licence and remediation can begin. Final closure activities are anticipated to be implemented in 2021.

The Board requires the concurrent execution of an independent quantitative risk assessment (QRA) during the review of the water license application. The QRA must be conducted on the site after it is cleaned up and the closure and reclamation plan is complete. The QRA does not consider existing risks or construction risks. 
The outcomes of the QRA are required to identify appropriate improvements and management responses to avoid or reduce the severity of predicted unacceptable risks. The requirements for the QRA include the following:

- Explicit acceptability thresholds determined in consultation with potentially affected communities.

- An examination of risks from a holistic perspective, integrating combined environmental, social, health, and financial consequences.

- Possible events of a worst-case/low frequency high consequence nature.

The requirement for potentially affected communities to participate in the Giant Mine QRA is unique. Potentially affected communities rarely participate in, or provide specific input to, QRA processes. An extensive literature review found no publicly available documentation of community involvement in QRAs conducted in natural resource industries.

Additionally, the approval and implementation of the closure and reclamation plan is occurring within the broader context of reconciliation with Indigenous people in Canada and growing requirements for the federal government to meaningfully engage Indigenous people on actions affecting their lands and resources. Together, the unique requirements and the context of reconciliation in Canada meant that the QRA team had to develop an innovative and fit-for-purpose engagement strategy.

The project team contracted Wood PLC (Wood) to complete the independent QRA to meet the requirements and to be in accordance with the most recent version of ISO 31000, Risk Management - Guidelines (International Organization of Standardization 2018). Stratos Inc. and SRK Consulting (Canada) Inc. were commissioned to plan and implement the engagement process for the QRA. Section 2 describes the engagement strategy and Section 3 highlights particularly innovative aspects of how the strategy was implemented during workshops with community members. Section 4 summarises selected engagement outcomes and Section 5 discusses other things that the team heard and learned throughout the process.

\section{$2 \quad$ Engagement strategy}

Stratos Inc. developed the engagement strategy to ensure that potentially affected communities could meaningfully participate in the technical QRA process developed by Wood PLC. The engagement strategy was designed to meet the requirements detailed in Section 1 and to deliver the following outcomes:

- Stakeholders understand the objectives and structure of the QRA, and are consulted throughout the QRA process.

- Potentially affected communities participate in determining acceptability thresholds.

- Other input from stakeholders is documented for consideration in project design and execution.

The engagement strategy was also designed to potentially contribute to other desirable outcomes, including:

- Stakeholders identify failure scenarios that did not occur to the QRA team.

- Failure scenarios are screened for inclusion in the QRA based on criteria relevant to potentially affected communities.

- Stakeholders accept and support the results of the QRA.

- The design and long-term oversight for the project are improved.

To this end, the engagement strategy was implemented in four phases. The first phase was to introduce the QRA methodology and validate the engagement approach with a small group of stakeholders. The second phase was to identify failure scenarios (called 'things that could go wrong' in plain language) with a broader group. The third phase was to discuss the type and severity of consequences of the failure scenarios and to agree on which failure scenarios had to go through the actual QRA. The fourth phase was to review the 
preliminary results with stakeholders before the results are refined or made public. The phases of the engagement strategy are shown in plain language format in Figure 2.

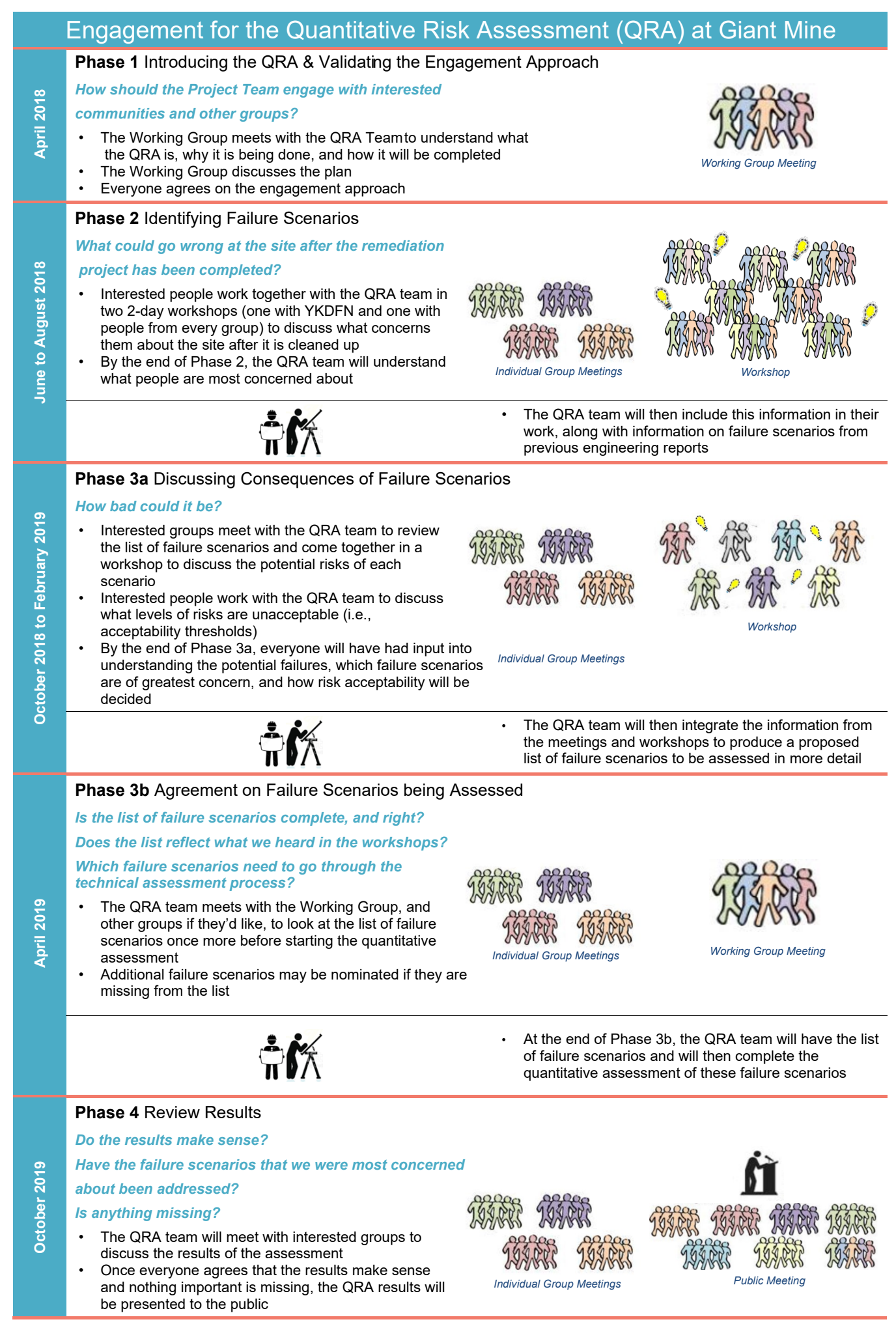

Figure 2 Summary of the quantitative risk assessment engagement process in plain language

The stakeholder groups that participated in the QRA process are summarised in Table 1. Each of these stakeholder groups has a representative on the Giant Mine Working Group; a group that meets monthly and makes recommendations to the project team. Table 2 summarises who participated in each workshop. 
Table 1 Stakeholder participant groups

\begin{tabular}{|c|c|}
\hline Stakeholder group & Description \\
\hline Yellowknives Dene First Nation (YKDFN) & $\begin{array}{l}\text { Indigenous government with members primarily living in } \\
\text { Dettah, N'Dilo and Yellowknife }\end{array}$ \\
\hline North Slave Métis Alliance (NSMA) & $\begin{array}{l}\text { Aboriginal rights-bearing Métis people of the Great Slave } \\
\text { Lake area, with members primarily living in Yellowknife }\end{array}$ \\
\hline Alternatives North & Social justice coalition based in Yellowknife \\
\hline City of Yellowknife & Local government \\
\hline Government of Northwest Territories & Territorial government, co-proponent of the project \\
\hline CIRNAC & Federal department, co-proponent of the project \\
\hline Public Services and Procurement Canada & Federal department \\
\hline Environment and Climate Change Canada & Federal department \\
\hline Health Canada & Federal department \\
\hline Fisheries and Oceans Canada & Federal department \\
\hline Giant Mine Oversight Board & Independent oversight body \\
\hline
\end{tabular}

Table 2 Workshop participation

\begin{tabular}{|c|c|c|}
\hline Engagement Strategy Phase & Timing & Participants \\
\hline Phase 1 & April 2018 & Limited to Working Group only \\
\hline \multicolumn{3}{|l|}{$\begin{array}{l}\text { Introduction of QRA methodology } \\
\text { and validation of engagement } \\
\text { approach }\end{array}$} \\
\hline Phase 2 & June 2018 (Yellowknife) & Unlimited participants from all groups \\
\hline Identifying failure scenarios & August 2018 (Dettah) & Special session for YKDFN in Dettah \\
\hline Phase 3a & October 2018 & Unlimited participants from all groups \\
\hline \multicolumn{3}{|l|}{$\begin{array}{l}\text { Discussing consequences of failure } \\
\text { scenarios }\end{array}$} \\
\hline Phase $3 a$, continued & December 2018 & Limited to Working Group only, with a \\
\hline $\begin{array}{l}\text { Determining acceptability } \\
\text { thresholds }\end{array}$ & February 2019 & $\begin{array}{l}\text { small number of additional YKDFN and } \\
\text { NSMA members }\end{array}$ \\
\hline Phase 3b & April 2019 & Unlimited participants from all groups \\
\hline $\begin{array}{l}\text { Agreement on failure scenarios } \\
\text { being assessed }\end{array}$ & & Special session for YKDFN in Dettah \\
\hline Phase 4 & October 2019 & To be determined \\
\hline Review results & & \\
\hline
\end{tabular}




\section{$3 \quad$ Highlighting innovation}

QRAs are highly technical exercises. It can be difficult for people without a risk assessment background to participate in the process or understand the results. The challenge for the QRA team was to execute the engagement strategy (described in Section 2) in a way that allowed all workshop attendees to meaningfully participate, even if they struggled with literacy or English fluency.

Three of the workshop exercises were particularly innovative and worked effectively to fulfil the objectives of the meetings which were the consequence criteria circle (Section 3.1), the probability poster (Section 3.2), the risk tolerance matrix (Section 3.3), communication of screening results (Section 3.4), and the Plain Language Report (Section 3.5).

\subsection{The consequence criteria circle}

The QRA team proposed consequence categories before the Phase 2 meetings in June and August 2018. One of the objectives of the Phase 2 meetings was to allow workshop participants to develop their own consequence categories in order to validate those that were developed by the team. Table 3 summarises the consequence categories that were proposed by the QRA team (left column), consequence categories that were identified in the workshop in Yellowknife (middle column), and consequence categories that were identified in the workshop in Dettah for YKDFN participants only (right column).

The categories identified in the Yellowknife workshop align closely with the categories proposed by the QRA team. During the workshop, participants noted the similarities between the categories and there was a sense that they agreed with the proposed categories.

The workshop in Dettah was more contentious. The facilitator suggested separating impacts to traditional knowledge/traditional land use (TK/TLU), impacts to the environment, and impacts to health and safety, which had occurred naturally in the Yellowknife workshop. YKDFN participants in the Dettah workshop were resistant to separating these three categories. They explained that, from their perspective, it is impossible to separate these kinds of impacts. The health of the people, the health of the environment, and the health of their traditional culture were intertwined; impacts to any of these impacted their way of life and their wellbeing. They criticised the QRA team for wanting to 'put information in boxes' and told them "put an end to the box... put it in a circle, the circle is our symbol." The translation team worked with several elders to determine the best word for 'way of life' in the Wiiliideh language: gonàowo.

Table 3 Comparison of consequence categories

\begin{tabular}{|c|c|c|}
\hline $\begin{array}{l}\text { Categories Proposed by the } \\
\text { QRA Team }\end{array}$ & $\begin{array}{l}\text { Categories Identified in } \\
\text { Yellowknife Workshop }\end{array}$ & $\begin{array}{l}\text { Categories Identified in Dettah } \\
\text { Workshop with YKDFN }\end{array}$ \\
\hline $\begin{array}{l}\text { Traditional } \\
\text { knowledge/traditional land use } \\
\text { (TK/TLU) }\end{array}$ & Traditional use/culture & Gonàowo (YKDFN way of life) \\
\hline Environment & Ecological & Gonàowo (YKDFN way of life) \\
\hline Health and safety & Human health & $\begin{array}{l}\text { Gonàowo (YKDFN way of } \\
\text { life)/health of future generations }\end{array}$ \\
\hline Socio-economic & Economic & $\begin{array}{l}\text { No reconciliation/financial impact } \\
\text { to YKDFN }\end{array}$ \\
\hline Direct financial (cost to project) & - & Financial impacts to project \\
\hline- & $\begin{array}{l}\text { Communication/loss of } \\
\text { knowledge/engagement }\end{array}$ & Communication \\
\hline- & - & Loss of trust \\
\hline
\end{tabular}


Based on this feedback, the QRA team developed the consequence criteria circle (Figure 3) for workshop participants to use instead of a table ('the box'). This circle was validated with a group of about 20 YKDFN members before it was finalised for use during the QRA process.

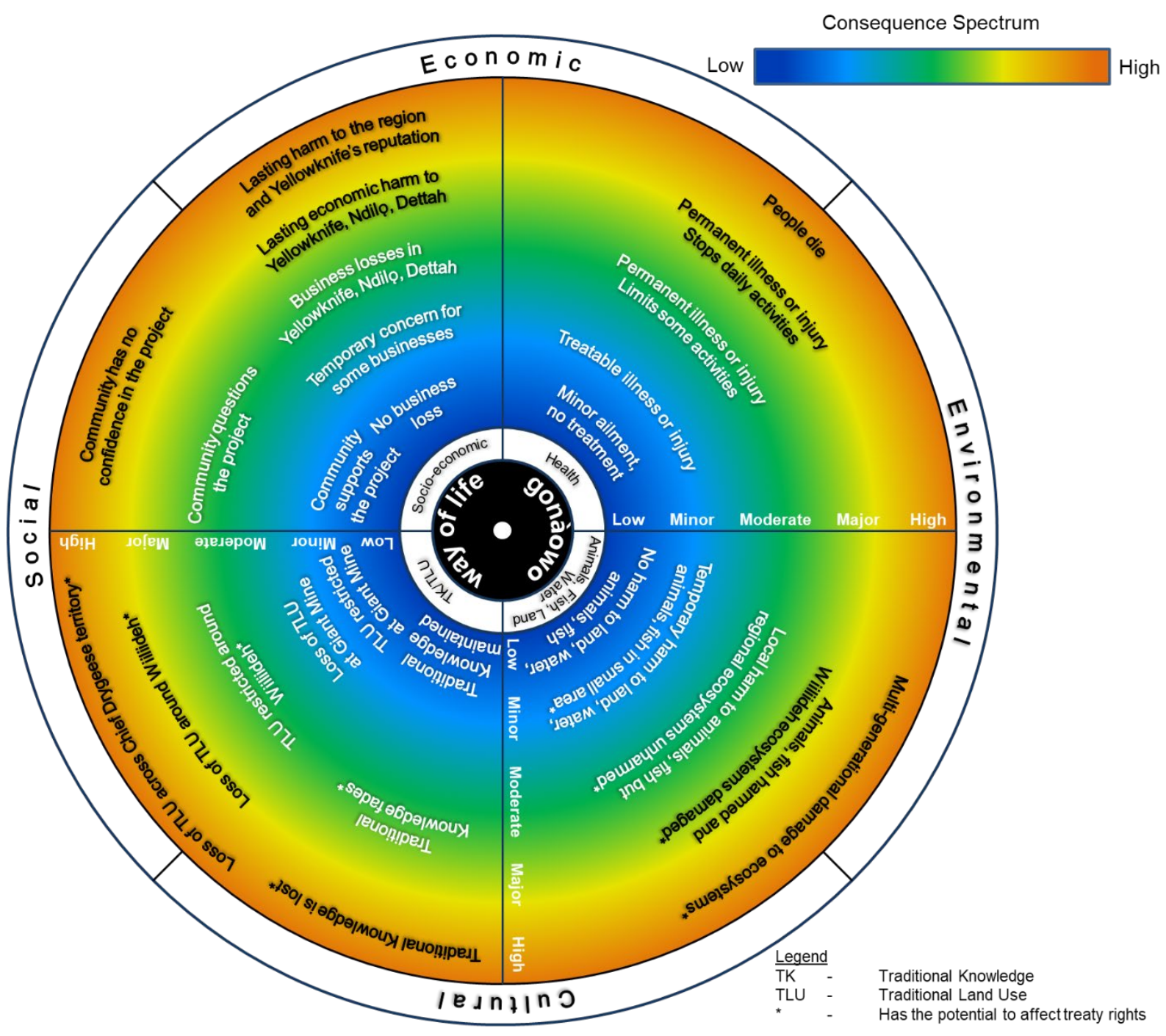

Figure 3 Consequence criteria circle, reflecting Indigenous perspectives on impacts from Giant Mine

Participants used the consequence criteria circle throughout the Phase 3a workshop. Several participants gave verbal feedback during the workshop that indicated that the circle made sense to them, was consistent with their worldview, and was easy to use (alongside other workshop participants who were using the more traditional table). Based on this success, the circle was carried forward through the rest of the QRA workshops.

\subsection{The probability poster}

The objective of the second part of Phase 3a was to develop acceptability thresholds which distinguish unacceptable risks from those that are 'as low as reasonably possible' (ALARP) or acceptable. The QRA team held two workshops with the Giant Mine Working Group and a small number of additional YKDFN and NSMA members in December 2018 and February 2019 to develop these thresholds (discussed in more detail in Section 3.3).

In order for the workshop participants to work through the thresholds, they had to have a good understanding of probability. The facilitator designed an exercise that had three goals. The first goal was to familiarise the participants with different ways of expressing probabilities (e.g. a ' 1 in 1,000' chance is the same as $0.1 \%, 1.0 \mathrm{E}-3$, and 0.001 ). The second goal was to give participants a feel for the differences in orders 
of magnitude (e.g. a ' 1 in 1,000 chance' compared to a ' 1 in 1,000,000' chance). The third goal was to compare the death rates (i.e. probabilities) associated with different activities such as driving, smoking, flying commercial airlines, and hang gliding.

The facilitator provided an initial overview of different levels of probability using a large sheet of banner paper with probability levels drawn to scale (Figure 4). Participants worked in small groups to develop their best guesses of the death rates for a provided list of activities and placed their guesses on the probability scale.

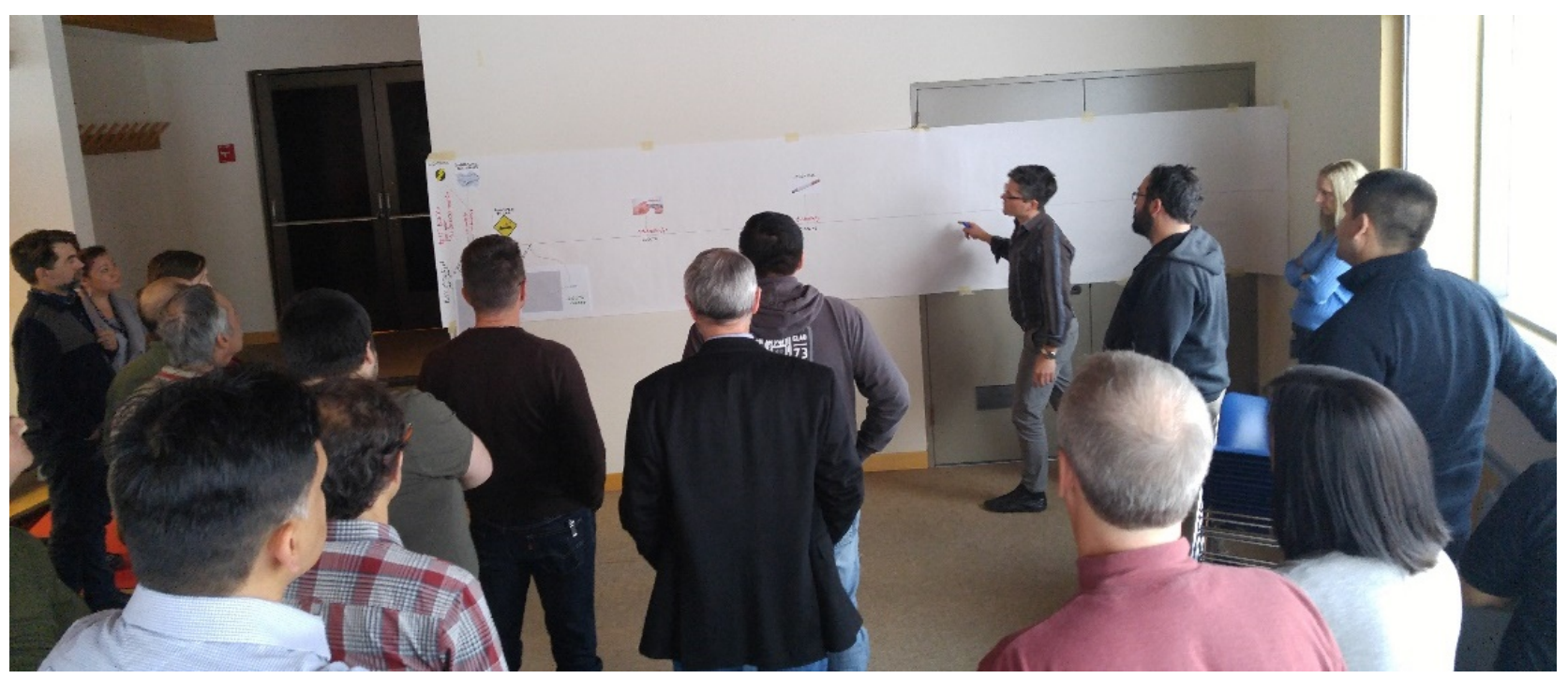

Figure 4 Exploring the probability poster in a facilitated exercise

The workshop participants referred to the probability poster throughout the remaining workshop. They seemed comfortable with probability notation and orders of magnitude and had a feel for what different levels of probability meant. This understanding allowed them to fully participate in the next exercise (Section 3.3).

\subsection{The risk tolerance matrix}

The QRA team facilitated exercises using risk tolerance matrices to validate proposed acceptability thresholds during the second part of Phase 3a (smaller meetings in December 2018 and February 2019).

Participants worked in small groups to complete risk tolerance matrices for different kinds of consequences (Section 3.1). They started with the matrix for human health where they indicated their acceptance of a consequence for different probabilities of occurrence (indicating 'yes' with a checkmark, or 'no' with an $\mathrm{x}$ ). The different rows in the health matrix corresponded with different levels of consequence severity, and the different columns in the matrix corresponded with different levels of probability. The completed matrix for human health is shown in Figure 5.

For the remaining matrices, the participants indicated their acceptance of a consequence for different probabilities of occurrence with an added option-the dash-which indicated that they would accept the risk if it was ALARP. The complete matrix for proposed draft aquatic environment thresholds is included as an example in Figure 6.

In Figures 5 and 6 , the green checkmark means that the risk was deemed acceptable by the small group, the red $\mathrm{x}$ means that the risk was not acceptable to the small group, and the blue dash means that the risk is acceptable if it was ALARP. 


\begin{tabular}{|c|c|c|c|c|c|}
\hline & $\begin{array}{c}\text { one in } \\
10 \text { million }\end{array}$ & $\begin{array}{c}\text { one in } \\
1 \text { million }\end{array}$ & $\begin{array}{l}\text { one in } 100 \\
\text { thousand }\end{array}$ & $\begin{array}{l}\text { one in } 10 \\
\text { thousand }\end{array}$ & $\begin{array}{c}\text { one in } 1 \\
\text { thousand }\end{array}$ \\
\hline \multicolumn{6}{|l|}{ Fatality } \\
\hline \multicolumn{6}{|l|}{$\begin{array}{l}\text { Severe illness } \\
\text { (cancer) }\end{array}$} \\
\hline \multicolumn{6}{|l|}{$\begin{array}{l}\text { Permanent illness } \\
\text { or injury } \\
\text { (diabetes, disability) }\end{array}$} \\
\hline \multicolumn{6}{|l|}{$\begin{array}{l}\text { Treatable injury } \\
\text { (broken leg) }\end{array}$} \\
\hline $\begin{array}{l}\text { Minor ailment not } \\
\text { needing treatment } \\
\text { (minor sprain) }\end{array}$ & & & & & \\
\hline
\end{tabular}

Note: the green checkmark indicates the risk is acceptable by a small group, and the red $\mathrm{x}$ indicates that the risk is not acceptable.

Figure 5 Risk tolerance matrix for health thresholds

\begin{tabular}{|c|c|c|c|c|c|}
\hline & $\begin{array}{c}\text { one in } \\
10 \text { million }\end{array}$ & $\begin{array}{c}\text { one in } \\
1 \text { million }\end{array}$ & $\begin{array}{l}\text { one in } 100 \\
\text { thousand }\end{array}$ & $\begin{array}{l}\text { one in } 10 \\
\text { thousand }\end{array}$ & $\begin{array}{l}\text { one in } 1 \\
\text { thousand }\end{array}$ \\
\hline $\begin{array}{l}\text { Site-specific water } \\
\text { quality objectives } \\
\text { are exceeded by } \\
100 \% \text { in Yellowknife } \\
\text { Bay beyond the } \\
\text { mixing zone for } 2 \\
\text { months in a year }\end{array}$ & & & & & \\
\hline $\begin{array}{l}\text { Untreated effluent } \\
\text { or mine water } \\
\text { seepage released } \\
\text { into in Yellowknife } \\
\text { Bay for } 2 \text { months in } \\
\text { a year }\end{array}$ & & & & & \\
\hline
\end{tabular}

Note: the green checkmark indicates the risk is acceptable by a small group, the red $\mathrm{x}$ indicates that the risk is not acceptable, and the blue dash indicates that the risk would be acceptable if it is also ALARP.

Figure 6 Risk tolerance matrix for aquatic environment thresholds

\subsection{Communication of screening results}

Wood PLC completed qualitative screening by determining the consequence and likelihood rankings for all 135 failure scenarios. Wood PLC determined independent consequence rankings for all five consequence categories (health, environment, socio-economic, financial, and TK/TLU). The results were plotted on a heat map (Figure 7).

Scenarios that were ranked in the orange moderate high, red high, and dark red very high boxes were determined to be important risks that warranted undergoing the detailed technical assessment process (i.e. were screened into the QRA). Scenarios that were ranked in the yellow moderate and green low boxes were 
determined to be less significant, and the QRA team proposed that these scenarios would be recorded, but would not undergo the detailed technical assessment (i.e. were screened out of the QRA).

\begin{tabular}{|c|c|c|c|c|c|c|}
\hline \multirow{5}{*}{ 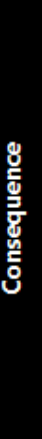 } & High & Moderate High & Moderate High & High & Very High & Very High \\
\hline & Major & Moderate & Moderate High & High & High & Very High \\
\hline & Moderate & Low & Moderate & Moderate High & Moderate High & High \\
\hline & Minor & Low & Low & Moderate & Moderate & Moderate High \\
\hline & Low & Low & Low & Low & Low & Low \\
\hline & & Very Unlikely & Unlikely & Possible & Likely & Very Likely \\
\hline
\end{tabular}

Figure 7 Heat map used for qualitative screening of failure scenarios

The objectives of the Phase $3 \mathrm{~b}$ workshops were to inform participants of the results of the screening process including which scenarios were proposed to go into the QRA and why, to provide an opportunity for participants to ask questions about why scenarios were screened in or screened out, and to provide an opportunity for participants to identify scenario rankings they consider need re-evaluation.

Both workshops were only one and a half days, and the QRA team faced the challenge of how to communicate the screening results for all 135 scenarios and still allow time for discussion so the workshop objectives could be met. The QRA team developed a number of handouts for the workshop participants. The most powerful handout was based on the consequence circle (Section 3.1), as shown in Figure 8.

Scenario No. 33 To Be Assessed in the QRA Contaminated Soils

People hunt and gather country foods from the site (examples: berries, medicinal plants and roots, animals), and are exposed to high arsenic through ingestion of these foods.

\section{Possible frequency ranking}

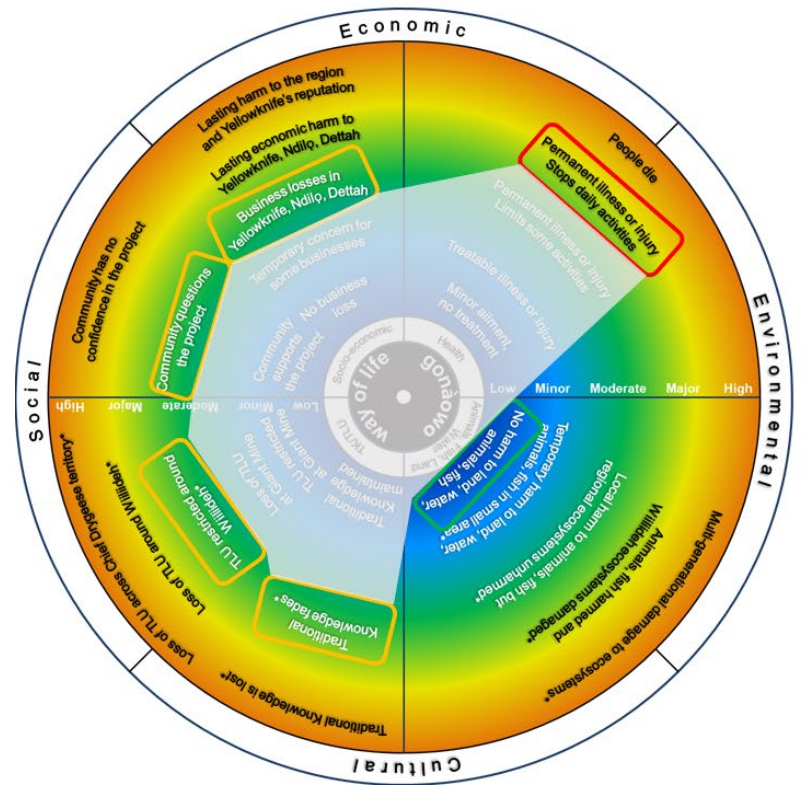

\author{
Scenario No. 34 \\ Contaminated Soils \\ Wind dispersion of dust from unremediated soils impacts the \\ Townsite.
}

Very Unlikely frequency ranking

Figure 8 Example page from a workshop handout, which shows screening results superimposed on the consequence circle 
This handout showed the consequence rankings on the consequence circle itself for four of the five consequence categories (health, environment, socio-economic, and TK/TLU). The farther away from the centre of the circle, the more serious the consequence. The colour of the boxes around the consequence description matches the colour of the heat map ranking (Figure 7). A grey polygon was added in the centre of the circle that connected the inside of the consequence ranking boxes. The bigger the polygon, the more significant the consequence rankings. Therefore, participants could understand the screening results at a glance.

Participants used this handout throughout the Phase $3 b$ workshop. Several participants gave verbal feedback during the workshops that this handout was easy to understand and allowed them to discuss the screening results efficiently.

\subsection{The Plain Language Report}

Many of the workshop participants and other members of potentially affected communities struggle with literacy or English fluency. The QRA team developed the 'Plain Language Report' for the QRA after Phase 3a, which was updated after the Phase $3 \mathrm{~b}$ workshops and will be updated after the Phase 4 workshop at the end of the QRA. The intention of the 'Plain Language Report' was to create a visually appealing way to discuss the most important parts of the QRA. The QRA team plans to record the text in both English and in Williideh Yatii, the traditional language of YKDFN, so the 'Plain Language Report' can work as a video for the literacy- and visually-impaired. An example page of the 'Plain Language Report' is shown in Figure 9.

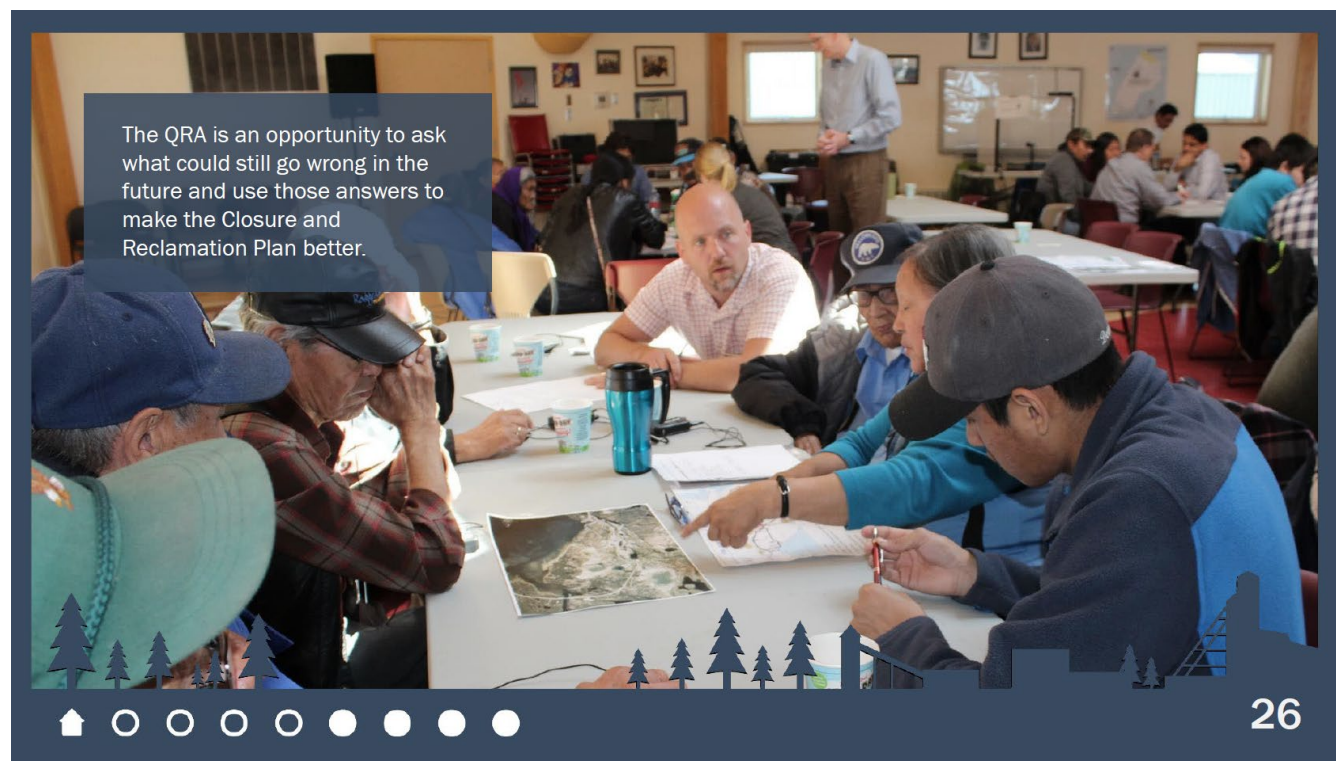

Figure 9 Example page from the 'Plain Language Report'

\section{$4 \quad$ Selected engagement outcomes}

To date, there have been eight workshops held to complete Phases 1 through $3 \mathrm{~b}$ of the engagement strategy and at least one more workshop will be held for Phase 4 before the QRA is complete (Section 2). There are several notable outcomes of the engagement work that has been conducted thus far.

During the two Phase 2 workshops, participants identified 435 different failure scenarios ('things that could go wrong'). This far exceeded the QRA team's expectations. These scenarios were communicated both in writing and verbally during the workshops, and the engagement team spent significant time reviewing these ideas and rewording them into representative failure scenarios. Some of the participant-generated failure scenarios were identical to scenarios that were identified from interviews with experts and engineering reports, and some of the failure scenarios were new. By combining identical ideas, the QRA team was able to identify 135 failure scenarios to go through the screening process in Phase 3b. Of these 135 failure scenarios, about 80 originated from the workshops. 
In addition to the above, during the Phase 2 workshops the QRA team was able to compare its proposed consequence categories to those that the participants had identified. As discussed in more detail in Section 3.1, the QRA team was able to validate the consequence categories once the consequence criteria circle was developed. The consequence criteria circle (Figure 3) allowed the QRA team to have buy-in from YKDFN participants to use the proposed consequence categories and enabled workshop participants to use the tool that made the most sense to them.

During the Phase 3a workshops, the QRA team was able to explore risk acceptability thresholds with a smaller number of participants. As discussed in more detail in Section 3.3, the QRA team used risk tolerance matrices to evaluate their proposed acceptability thresholds for different kinds of consequences. While this exercise revealed that some participants did not always agree with the proposed acceptability thresholds, it allowed the QRA team to understand how perspectives differed and why.

During the Phase $3 \mathrm{~b}$ workshops, workshop participants reviewed the results of the qualitative screening to make sure that their concerns were reflected in the failure scenarios screened in to the QRA for the detailed technical assessment. As discussed in Section 3.4, the QRA team used a variation of the consequence circle (Section 3.1) to communicate the screening results effectively and achieve buy-in from participants.

The QRA team improved how workshops were facilitated to achieve better engagement outcomes throughout the process. The team recognised that, for many elders, storytelling is their preferred way to communicate their perspectives. The team recorded verbatim what elders said and spent time digesting this information after the workshops to make sure that the elders' points of view were included in the process. The QRA team also balanced the efficacy of working in small groups versus the need for translation and the desire for everyone within the community to hear what the elders had to say in designing the workshops. Several times, the structure of the workshop was switched to move either from plenary into small groups, or from small groups into plenary, to accommodate the needs of the community and allow the elders to participate. The QRA team learned that it was necessary to be flexible and adapt the workshop agenda and activities on the fly; there is always more than one way to fulfil the objectives of a workshop.

\section{$5 \quad$ What we heard and learned}

The workshops resulted in specific outcomes that were needed to complete the QRA (Section 4). However, the QRA team also heard other information from the workshop participants. Some of this feedback was an opportunity for 'lessons learned' to improve subsequent workshops and some of this feedback resulted in increased cultural awareness and sensitivity.

The health of the people, the health of the environment, and the health of their traditional culture are intertwined for many Indigenous people, including YKDFN members. People became frustrated when they felt like engineers were imposing 'boxes' on their thinking and were not considering Indigenous worldview. This difference in perspective resulted in the development of the consequence criteria circle (Section 3.1, Figure 3).

Many YKDFN members wanted to include risks to the achievement of socio-economic benefits in the QRA. The socio-economic strategy for the project is separate from the closure and reclamation plan and therefore, risks to achieving socio-economic benefits are out of the scope of the QRA. This separation of the technical (environmental) and social elements of closure was not consistent with the Indigenous worldview of many participants.

The Indigenous communities involved in the QRA have very different perspectives on time than the engineers. The Giant Mine Remediation Project has a 100-year time frame, but many participants wanted to talk about what could happen in the next 10,000 years, not just the next 100 years. Many people brought up their concerns about potential impacts to future generations thousands of years in the future and feeling responsibility for their wellbeing; this is aligned with an Indigenous sense of guardianship that was also expressed during the workshops. 
In a similar vein, participants from all stakeholder groups expressed mistrust of the longevity and reliability of institutional controls and government funding. Some people seemed to think it was likely, or perhaps even inevitable, that the long-term management of the site would be threatened in this manner. These perceptions and sentiments may be rooted in the mine's legacy of significant environmental and health impacts on local communities.

Characterising failure scenarios can be challenging for some stakeholders. There was a reluctance to speak out loud about 'bad things that could happen' and giving power to those words. In general, there was reticence among the YKDFN members about speaking about negative impacts in the future. People preferred to talk about risk mitigation; positive ways to make sure failure scenarios don't happen and to respond to them if they do.

When brainstorming failure scenarios, participants were inspired by historical events. Some of these examples initially seemed somewhat extreme to the QRA team, but were later corroborated. The most memorable examples include:

- Wildfires closing the highway to Yellowknife from the south (wildfire smoke was so thick during the summer of 2014 that stores started running out of fresh produce and the highway to Yellowknife was shut down in late May 2019 due to an out-of-control wildfire).

- Terrorism threatening the stability of the frozen arsenic underground (a bomb planted in the underground mine during strikes in 1992 killed nine people).

- A plane crashed into the site (a missile fell off of a Canadian Forces jet, landing on Yellowknife's golf course, in 2004).

\section{Conclusion}

The QRA team designed the engagement strategy to consult with stakeholders throughout the QRA process, inform stakeholders about the objectives and structure of the QRA, consult with potentially affected communities to determine acceptability thresholds, and document other input for consideration in project design and execution (Section 2). The engagement strategy successfully fulfilled those objectives.

The engagement strategy was implemented in four phases. The first phase was to introduce the QRA methodology and validate the engagement approach with a small group of stakeholders. The second phase was to identify failure scenarios with a broader group. The third phase was to discuss the type and severity of consequences of the failure scenarios and to agree on which failure scenarios had to go through the actual QRA. The fourth phase was to review the preliminary results with stakeholders before the results are refined or made public.

The QRA team used a number of innovative tools to allow workshop attendees to meaningfully participate. These include the consequence criteria circle, the probability poster, the risk tolerance matrix, and the 'Plain Language Report'. Feedback received during the workshops indicated that participants were satisfied with these tools, and in some cases that the tools exceeded their expectations. This high level of participation translated to concrete, thorough engagement outcomes that the QRA team used in subsequent phases of the project. The results of the QRA will be available late in 2019.

\section{Acknowledgement}

The authors thank the Giant Mine stakeholders for their dedication and commitment throughout the QRA process.

\section{References}

International Organization of Standardization 2018, Risk Management - Guidelines (ISO 31000:2018), Geneva. 
